\title{
Increasing interest in social studies: Social perspective taking and self-efficacy in stimulating simulations
}

\section{Citation}

Gehlbach, Hunter, Scott W. Brown, Andri loannou, Mark A. Boyer, Natalie Hudson, Anat NivSolomon, Donalyn Maneggia, and Laura Janik. 2008. "Increasing interest in social studies: Social perspective taking and self-efficacy in stimulating simulations." Contemporary Educational Psychology 33 (4) (October): 894-914. doi:10.1016/j.cedpsych.2007.11.002. http:// dx.doi.org/10.1016/j.cedpsych.2007.11.002.

\section{Published Version}

doi:10.1016/j.cedpsych.2007.11.002

\section{Permanent link}

http://nrs.harvard.edu/urn-3:HUL.InstRepos:11385610

\section{Terms of Use}

This article was downloaded from Harvard University's DASH repository, and is made available under the terms and conditions applicable to Other Posted Material, as set forth at http:// nrs.harvard.edu/urn-3:HUL.InstRepos:dash.current.terms-of-use\#LAA

\section{Share Your Story}

The Harvard community has made this article openly available. Please share how this access benefits you. Submit a story. 
Increasing Interest in Social Studies:

Social Perspective Taking and Self-Efficacy in Stimulating Simulations

Hunter Gehlbach

Harvard University

Scott W. Brown, Andri Ioannou, Mark A. Boyer, Natalie Hudson, Anat Niv-Solomon, Donalyn Maneggia, \& Laura Janik University of Connecticut

Please send correspondences to:

Hunter Gehlbach

hunter_gehlbach@gse.harvard.edu

W: (617) 496-7318

Fax: (617) 495-9268

Running Head: INCREASING INTEREST IN SOCIAL STUDIES 
INCREASING INTEREST IN SOCIAL STUDIES

\begin{abstract}
:
This study examined the potential of simulations to bolster interest in middle school social studies classrooms. Using a pre-post design, we examined 305 middle school students (49\% female) who participated in the web-based GlobalEd simulation. Unlike the motivation declines middle school students usually experience, participants in this simulation became more interested in social studies. We investigated four hypotheses as to why these increases may have occurred. We found no support for the possibility that, (a) students' interest in a particular issue area or (b) their increased valuing of the subject matter, were related to their increased interest. However, results suggested that, (c) the challenging nature of the activity may have bolstered their interest in social studies and (d) students' increased propensity to engage in social perspective taking. The discussion explores future research directions and whether implications for classroom teachers are warranted given the correlational nature of the research.
\end{abstract}

Keywords: Interest, Social perspective taking, Motivation, Self-efficacy, History, Social studies, Simulations, Middle school, Global studies 


\section{Increasing Interest in Social Studies:}

\section{Stimulating Simulations, Self-Efficacy, and Social Perspective Taking}

For many secondary school teachers, sparking student interest in their particular discipline can be a Herculean challenge. The magnitude of this challenge is greater for some teachers than for others. For social studies teachers, students often perceive their subject matter as less interesting and important than other school subjects (Stodolsky, Salk, \& Glaessner, 1991; Wolters \& Pintrich, 1998). These perceptions are likely exacerbated by teachers attempting to cover a vast amount of content at a necessarily superficial level (VanSledright \& Limon, 2006). Specifically, when teachers try to cover so much so quickly (perhaps because of pressure from the No Child Left Behind program and standardized testing), very few issues come alive or seem personally relevant. Even in the best cases, students will likely find themselves engaged in learning about others' opinions regarding history, geography, politics, and economics rather than developing their own narratives and explanations. Thus, students may also find social studies uninteresting and unimportant because they rarely have the opportunity to actively engage in the "doing" of social science (Kobrin, Abbott, Ellinwood, \& Horton, 1993).

Motivating student interest can be equally challenging for middle school teachers. Eccles et al. (1993) describe early adolescents as being particularly at risk for decreases in motivation as they enter and advance through the middle school or junior high grades. A diverse body of research indicates that studies of interest parallel this larger trend. Using a

cross sectional approach with $4^{\text {th }}-12^{\text {th }}$ graders, Epstein and McPartland (1976) found that there was a significant, negative relationship between interest and grade level. In a longitudinal approach, focused only on junior high students, Pintrich (2000) found that students' task value for math class (operationalized by a scale consisting of interest and utility value items) declined during eighth grade. This decline appears to occur outside the United States as well. In a sample of Australian middle and high school students, Watt (2004) found that students' intrinsic valuing of math and English declined during middle school as did their perceptions of the utility value of these subjects. There is also evidence that this trend generalizes across different conceptions of interest. Using a 
conceptualization that included realistic, investigative, artistic, social, enterprising, and conventional sub-types of interest, Tracey (2002) showed that student interest for all six sub-types dropped during seventh grade. The comprehensive review provided by Wigfield, Byrnes, and Eccles (2006) illustrate that the declines in motivational constructs such as interest during middle school are robust and pervasive. Pintrich and Schunk summarize that the, "research clearly shows that students' interest in school and school tasks does decline with age” (2002, p. 296).

Given these findings, middle school social studies classrooms provide uniquely challenging settings for exploring how educators might motivate students to become interested in a subject matter. In this study, we focus on this challenging motivational environment and explore a possible pathway for motivating middle school students to become more interested in social studies. Specifically, we examine a web-based, roleplaying simulation called GlobalEd. Two sets of broad research questions are investigated:

1) To what extent does participation in the GlobalEd simulation impact students' interest in social studies?

2) What explanations can plausibly account for students' changes in interest in social studies changes from the beginning to the end of the simulation? Which explanations can be ruled out?

In this article, we first describe some of the past work on simulations. Then we detail the specifics and procedures of the GlobalEd simulation. Next, we offer some theoretical explanations as to why simulations might effectively motivate interest in social studies for middle school students. We conclude the introductory section by presenting the four specific hypotheses related to the second research question that we tested.

\section{Past research on simulations}

Simulations have long been perceived as activities that facilitate student learning and motivation. However, two major questions arise for secondary school social studies teachers thinking about implementing simulations. First, will the findings from past simulation research will generalize across settings? Much of the research documenting the success of simulations has come from higher education or from science classrooms. 
Whether these findings extend to different age groups or different subject matters is unclear. Second, will the results of smaller case studies be replicated for a larger quantitative study? Although some evaluations of simulations have looked at student learning in a rigorous and systematic way, most of the assessments of simulations' impact on student motivation have been anecdotal.

Lay and Smarick (2006) provide an illustrative case of a successful simulation at the higher education level. They assessed the effectiveness of a U.S. Senate simulation as a tool for college students learning about American politics. The goal of the simulation was to have students experience law-making procedures so that they better understood the process and appreciated the institutions at the core of the U.S. political system. Their evaluation of the simulation used pre- and post-measures of knowledge and attitudes to compare two introductory “American Government” classes. One class utilized traditional teaching methods such as lectures and tests, while the other supplemented these traditional methods with the online simulation. They found that students who participated in the simulation gained more knowledge, became less cynical, and became more confident about their knowledge of the legislative process as compared to their peers in the traditional class.

In secondary school science, the "River City” simulation (Dede, Clarke, Ketelhut, Nelson, \& Bowman, 2005) stands out as exemplary - both in its content and in the evaluation of the simulation. River City employs a multi-user, virtual environment. Learners actively investigate complex, real-world problems and interact with novices and experts who are part of the environment to facilitate their problem-solving. Specifically, students work in teams to find out why River City’s citizens are plagued by various illnesses. Several experiments from Dede and his colleagues showed that River City participants learn standards-based biological content and complex inquiry skills better than students receiving other good traditional approaches. In terms of motivation, findings also indicate that students and teachers in River City classrooms are highly engaged, student self-efficacy increases, student attendance improves, and disruptive student behavior drops (Dede et al., 2005).

Although these examples provide solid evidence that simulations can be effective tools for learning and motivational outcomes, it is not clear whether these findings 
generalize to simulations in middle school social studies classrooms. College students have much more autonomy to choose classes that they are interested in than secondary school students. Thus, as compared to middle school students, undergraduates are likely to be much more motivated, for their social science courses and for simulations within those courses. In secondary school science simulations, students often engage in discovery learning and "hands-on” laboratory explorations (Ronen \& Eliahu, 2000). By contrast, social studies simulations usually take the form of "role-play simulations" or "gamesimulations”, where learners engage in collaborative problem solving of world issues. While these simulations may provide a helpful review of previously learned content, the opportunities for the type of discovery learning often present in science simulations may be less prevalent in social studies classrooms. Thus, participants in science simulations may be motivated by exciting opportunities to uncover new knowledge as well as social features of the learning environment. By contrast, the motivational benefits of social studies simulations may be more limited to features of the social aspects of the learning environment. At this point, generalizing directly from higher education or science to social studies simulations seems imprudent.

What we do know about social studies simulations at the secondary school level, relies heavily on anecdotal evidence. For example, Civilization III is a promising historical computer strategy game and has unique affordances as a historical, geographic, and political simulation. A number of educators have advocated using Civilization III mainly for its engaging properties (Hope, 1996; Prensky, 2001; Teague \& Teague, 1995). In a non-computer based simulation, Tamura (1992) engaged high school students in a role-play to motivate them learn about how government works. Students took roles of legislators and lobbyists, argued their positions, and wrote persuasive essays. In another example, Pace, Bishel, Beck, Holquist, and Makowski (1990) conducted a simulation of the Cuban Missile Crisis. Although all three simulations were perceived by the researchers as effective in engaging students, the researchers did not directly assess student motivation. This approach to investigating the efficacy of simulations in social studies appears to typify the research in this area.

Although Alleman and Brophy’s (1993) did not study simulations directly, their study of what pre-service social studies teachers recalled from their own K-8 social studies 
experiences does provide an empirically rigorous exception to this heavily-anecdotal body of research. They found that when the pre-service teachers did recall participating in a simulation, that memory tended to be associated with recollections of something that was learned during the experience. In some instances the memories were also associated with positive affect, indicating that these simulations had probably been motivating experiences for at least some of the participants. Of the 138 recollections of social studies activities that met the authors' criteria for being a "best activity," 24 of them were simulation experiences (Alleman \& Brophy, 1994). However, the authors do acknowledge that, "Many of the most memorable simulations occurred in the K-3 and 4-6 grade levels" (p. 44).

To summarize, we have compelling evidence that simulations can be effective teaching tools at the higher education level and in science classes. In these settings, simulations can bolster student learning and may also enhance student motivation. However, in settings where the motivational challenges may be greatest, i.e., middle school social studies classrooms it remains unclear whether simulations will still serve as an effective motivational tool. Furthermore, if simulations are effective in getting students more interested in social studies, there is still a critical need to know which aspects of the simulations are promoting student interest.

\section{The GlobalEd simulation}

GlobalEd is a five-week web-based simulation in which students negotiate treaties involving current world issues while taking the perspective of the country they are representing. The GlobalEd simulation is one of a number of simulations that has evolved out of the International Communication and Negotiation Simulations at the University of Maryland. Students participate in the simulation as a part of their school's social studies course. Prior to the start of the simulation, each class is assigned to represent a real-world country (e.g., France, Nigeria, or China). Within each class, students are also assigned to a “issue area”. This small group of students focuses on one of five topics. Topics included: International Conflict and Cooperation (e.g., conventional arms control in the developing world), Human Rights (e.g., child labor), World Health (e.g., AIDS education and prevention in the developing world), Global Environment (e.g., global warming), and U.N. 
Security Council Reform. Although the broad topical areas stay consistent from year to year, the specific topics vary depending on current "hot" topics in world affairs and feedback from the teachers about how well different issues worked in their classrooms in previous years.

In the weeks leading up to the simulation, students research their countries and issue area. During the simulation, they interact through synchronous "live chat" conferences and through asynchronous email correspondences. Students communicate with "representatives" from the other countries who are focused on the same issue area. For example, the Chinese Human Rights group might communicate with Human Rights groups from Brazil, England, and Kenya. Each group strives to make agreements or treaties with other countries in the simulation. It is student engagement in this negotiation process, rather than the creation of specific "formal agreements," that is the main goal of the simulation. These communications are moderated by a simulation controller (“SIMCON”). SIMCON monitors the civility of the student interactions and ensures that countries do not make agreements prematurely, i.e., without thinking through all of the issues involved. In addition, SIMCON ensures that the representatives of different countries remain true to their roles. Unbeknownst to the middle school students, the United States is played by a research assistant working on the project, thus, all students have to engage in taking the perspective of a foreign country.

\section{Why simulations might motivate students’ interest}

Although interest has been associated with numerous valued educational outcomes such as knowledge (Alexander, Schulze, \& Kulikowich, 1994), interest has been particularly closely associated with motivation. Different theoretical approaches connect “interest” and “motivation” in a variety of ways. Hidi and Renninger (2006) describe interest as a "psychological state of engaging or the predisposition to reengage with particular classes of objects, events, or ideas over time” (p. 112). Interest consists of affective and cognitive dimensions and develops through four phases: triggered situational interest, maintained situational interest, emerging individual interest, and well-developed individual interest. 
For the present study, we have adopted this conception of interest with the following caveat. According to Hidi and Renninger, situational and individual interest are always motivating. Other motivational theories present interest as a component of motivation but imply that interest alone will not result in motivation. For example, in Ford's (1992) theory, motivation consists of goals, emotions, and personal agency beliefs. Interest may play a role in guiding the selection of certain goals that students might pursue or in helping generate the emotion and energy for students to pursue such goals. However, in Ford's conception, one can be interested in a domain without setting goals to pursue that domain. Consequently, one can be interested without being motivated. In Eccles-Parsons et al. (1983) expectancy-value theory, motivation consists of students' expectations for success on a given task and their valuing of that task. In this approach, interest is one of four types of task value: intrinsic/interest value, attainment value, utility value, and cost. This approach also allows one to be interested in a domain without being motivated to pursue goals in that domain (e.g., if one is interested but does not expect success).

Although these scholars maintain differing perspectives as to whether interest will necessarily result in motivation, they would likely concur that increasing students' interest in subjects such as social studies is a desirable outcome. Thus, for our purposes, we conceptualize interest similarly to Hidi and Renninger (2006) and view it as a desirable outcome in its own right. However, we view it as a key component of student motivation rather than as a psychological state that is necessarily motivating. This section explores four possibilities for how simulations might impact students’ interest in social studies.

As indicated above, Hidi and Renninger's (2006) four-phase model focuses on the transition from interest being supported by aspects of the situation to being sustained by the individual. As students' interest in a particular content area progresses towards individual interest, knowledge becomes increasingly important and can often perpetuate the development of interest. For example, as students become interested in a particular content, they may begin to ask more self-generated questions out of curiosity. Answers to these curiosity questions help students become more knowledgeable, which in turn might raise new curiosities. It seems plausible that the GlobalEd simulation might facilitate students' interest in social studies because students develop a particular area of expertise through research on their issue area. For example, as students become more 
knowledgeable about Russia’s role in the U.N. Security Council, they might become more curious about how it evolved. This interplay between curiosity and knowledge may help students' interest become more internalized and may help their interest generalize to other domains. For example, if these feelings extend from their particular research topic to related areas it seems possible that students could become more interested in social studies.

In Eccles-Parsons et al. (1983), previously-mentioned 'expectancy-value’ theory, students' valuing of a specific task depends on their perceptions of the task's intrinsic/interest value, attainment value, utility value, and cost. Other scholars have conceptualized importance as a sub-component of interest (Schiefele, 1996). Thus, students' interest in a particular subject matter and their view of its importance are intimately related. Interest and importance are, however, conceptually distinct. Students might view one subject as interesting but not very important (e.g., an elective class), while another (perhaps math) might be seen as important but uninteresting. In the GlobalEd simulation, students may find themselves reassessing the importance of social studies and becoming more interested as a result. Although social studies has traditionally been viewed by students as unimportant (Stodolsky et al., 1991), it seems reasonable to think that as students apply their issue area knowledge and negotiate about current world issues, they may come to see social studies as increasingly important and relevant to their personal lives. As social psychologists have shown through research on the self-reference effect, people are particularly attuned to self-relevant information (Symons \& Johnson, 1997).

According to Ford's (1992) theory of motivation, the principle of optimal challenge states that, "motivation is maximized under conditions of 'optimal challenge' - that is, conditions in which standards for goal attainment are difficult given the person's current level of expertise, but still attainable with vigorous or persistent effort” (p. 211-2). This idea follows from White's (1959) notion that we need an optimal amount of stimulation or an optimal level of arousal to perform well on a task (see also Csikszentmihalyi, 1991). If we are completely confident in our ability to succeed on a task, we will normally be unmotivated to attempt it; completing the task will merely confirm that we could succeed on the task (which we already knew). However, for optimally challenging tasks where we are necessarily less confident in the future outcome, we are more motivated because succeeding (or failing) on these tasks provides us with information that helps us learn. A 
simulation such as GlobalEd could potentially present more of an optimal challenge for most middle school students than their usual schoolwork, which often consists of cognitively unchallenging, uncreative tasks (Eccles et al., 1993). Thus, although students might be less confident about their ability to succeed in the simulation activities, these more challenging tasks might bolster their interest in their social studies class.

A final possibility emerges from a group of historians who have conducted simulations with secondary school students. Pace et al., (1990) were attracted to the perspective taking aspect of the role-playing required for their simulation of the Cuban Missile Crisis. Specifically, their students had to wrestle with different perspectives in different ways. As representatives of a nation, students came into conflict with the ideologies of the representatives of other nations. In addition, they had to contend with the internal politics of each of the nations involved and had to negotiate the differing points of view of their peers. Thus, students in this simulation had to frequently engage in social perspective taking (SPT) i.e., they had to discern the thoughts and emotions of others and often had to assess others' perceptions of the situation. The authors intuited that the need to engage in SPT regularly for students in their simulation might be particularly motivating. For middle school students, the opportunities to regularly engage in SPT may be particularly valued. Students at this developmental stage have recently developed the capacity to engage in thinking about the mental worlds of others at a sophisticated level (Keating, 1990) and are often engaged in trying to figure out what their classmates think about them (Eccles et al., 1993). Because GlobalEd also offers intense and protracted perspective taking opportunities, we hypothesized that students might become similarly interested in social studies. In other words, if SPT is particularly interesting to middle school students, and students come to see social studies as a setting that encourages and rewards SPT, students may become more interested in the discipline.

\section{Hypotheses}

The first research question that guides this study examines the extent to which students' interest in social studies changes over the course of this simulation. In addition, it is sensible to investigate whether changes in interest occurred differentially for males versus females, older versus younger students, or for students of different races. These 
sub-group analyses might help shed light on whether the simulation is particularly effective or ineffective for different groups of students.

The second research question asks why these changes may have occurred. Specifically, we test four hypotheses that follow directly from the aforementioned explanations as to how the GlobalEd simulation might impact students' interest:

1) Students become more interested in the specific topic that they research during the simulation. As students research a particular issue area in depth, they become more knowledgeable and curious about that area, which, in turn, generalizes to more overall interest in social studies.

2) Because of their experience in the simulation, students view social studies as more important. Through the simulation, students see how social studies is actually enacted in the real world, develop a new appreciation of how important it is, and consequently, become more interested in it.

3) Through the simulation, students realize that social studies is more challenging than they had originally thought. In contrast to a subject like mathematics, students have not viewed social studies as a challenging discipline (Stodolsky et al., 1991). By engaging in the challenging problem-solving activities of the simulation, students begin to perceive social studies as an optimally challenging, and therefore more interesting, subject.

4) Students engage in SPT more frequently during the simulation. The simulation encourages them to engage in a type of thinking that is different from their regular class, but that they are intrinsically motivated to develop. As students begin to perceive social studies class as a venue in which they can continue developing SPT, they become more interested in the discipline.

Method

Participants. Students from 19 schools located throughout the United States participated in the study. Most schools in the sample were near the national average in their achievement level and socio-economic status. Participants $(N=305)$ included a balanced proportion of males (51\%) and females. White students (73\%) made up the majority of the sample; Asians (10\%), African-Americans (8\%), and Latinos (5\%) comprised the other major groups in this sample. Eighth graders (61\%) comprised the majority of the participants, followed by $7^{\text {th }}$ graders $(27 \%), 6^{\text {th }}$ graders $(9 \%)$, and $5^{\text {th }}$ 
graders (3\%). In using race and grade-level as variables in our analyses, we collapsed the former into two categories ("white” and "non-white”) and the latter into three categories (by combining the $5^{\text {th }}$ and $6^{\text {th }}$ graders). These aggregations allowed for a sufficient $n$ to potentially detect between-group differences.

Measures. In addition to demographic variables, the measures included pre- and post- assessments for interest in social studies, interest in issue area, importance of social studies, self-efficacy in social studies, and SPT (see the Appendix). A multiple choice test of content knowledge covering the social studies material that students were studying during the simulation was also given to students prior to and after the simulation.

For our main dependent measure, we developed a measure of interest to be congruent with Hidi and Renninger's (2006) theory. Some items tapped students' interest in social studies when it was likely sparked by the classroom situation (e.g., item 4), while others examined instances when students' individual interest persisted beyond that context (e.g., item 2). The scale also included general items such as "Overall, how interesting do you find your social studies class?” Thus, students scoring highly across all six items on the Interest in social studies scale ( $\alpha=.85$ for pre and .87 for post) should be more developed in terms of their interest in social studies.

Our first independent measure, students' Interest in issue area (i.e., the topic they focused on in the simulation) assessed students' relative interest in their topic by asking them to rank order all five topics from most interesting (1) to least interesting (5). Importance of social studies was assessed by having students rank how important they perceived social studies to be relative to English, math, and science from most important (1) to least important (4). Social studies self-efficacy was a 5-item rating scale ( $\alpha=.79$ for pre and .82 for post) that assessed how confident students were that they could meet the expectations of the class; for example, "How confident are you that you can learn all the material presented in this class?” This measure represents an adaptation of the Midgley et al. (2000) academic efficacy scale. SPT was a 7-item rating scale ( $\alpha=.88$ for pre and post) adapted from Davis’ (1996) scale that asked students to assess how frequently they tried to figure out the thoughts and feelings of others. Items included, "Before criticizing others, how often do you imagine how you would feel if you were in their place?” 
The multiple choice test had reliability estimates of $\alpha=.53$ for pre and .72 for post. It included questions such as "Global warming is most often blamed on: (Industrialization byproducts, Deforestation, The burning of fossil fuels, All of the above)”.

Procedures. Teachers were initially recruited to participate in GlobalEd simulations several years before this evaluation began and have continued to participate annually on a voluntary basis. New teachers who learn about the simulation through colleagues or the website have also joined on a voluntary basis. The curriculum that students use to educate themselves about their country and issue area is posted online at www.xxxxx.globaled.edu. Thus, students are all exposed to the same basic material (though some students may pursue additional sources on their own), including an extensive on-line research library and a simulation scenario that lays out the fundamental problems in each issue area. The scenario deals with real-world issues and is set about six months into the future to prevent students from "playing out the newspaper.” Students completed the assessment instruments online as they began researching for the simulation and within two weeks of the simulation's conclusion. They research their topics for approximately 68 weeks prior to the start of the simulation. Once the simulation begins, student groups send messages at their convenience and/or as assigned by their teacher. Each issue group participates in two synchronous, issue-specific conferences during the simulation. All countries, and the issue-groups within them, take part in a debriefing conference after the simulation is complete.

During the simulation period the email correspondences allow students to negotiate over the issues laid out in the simulation scenario. During this process, they must work within their issue groups to decide their country’s policy and discuss responses to proposals from other countries. In addition, they also negotiate within their country-teams to establish coherence across issue areas. For example, students working on India's human rights policy must coordinate with their classmates working on India’s environmental policy. In this way, the students are engaged in two-level negotiations (i.e., within their country-team and across country-teams) throughout the simulation period (see Putnam, 1988). Synchronous conferences are held to simulate face-to-face diplomatic interactions and compress the interactions into hour-long "chats” facilitated by SIMCON. 
Classroom teachers participating in GlobalEd are encouraged to take on the role of facilitators with their country-teams. GlobalEd has been embedded within their social studies curriculum and thus dominates the classroom environment for nearly a semester. As such, teachers deliver their often-mandated content in typical ways around the simulation, but once the simulation begins, teachers primarily focus on questioning, promoting research of the problems at hand and developing critical thinking around the issues. A wide array of exercises has been developed by GlobalEd teachers and is available on the program's web-site to serve these goals. Teachers also generally assign students to specific issue-groups. These assignments are partly based on student interest, but teachers also try to balance gender and other classroom management concerns. Each teacher develops his or her own evaluation methods for grading purposes that are separate from the instruments administered by GlobalEd.

\section{$\underline{\text { Results }}$}

To address our first research question, we determined the nature and magnitude of the change in interest that students experienced. On the 5-point scale mentioned above, students' interest in social studies increased significantly from pre $(M=3.34)$ to post $(M=$ $3.50 ; t_{(191)}=3.82, p<.001$; Cohen's $d=.21$ ). This increase did not appear to be the result of a small group of particular teachers as students in all but one classroom experienced a gain in interest (see Figure 1). To probe this result further, three repeated measures ANOVAs were conducted while including different factors (specifically gender, race, and grade level) to examine whether this increase in interest occurred differentially for different subpopulations. No evidence of gender differences $\left(F_{1,190)}=1.53, p=.22\right)$ emerged. The change in interest was the same for students of different races and grade levels. However, non-white students $\left(F_{1,190)}=5.46, p=.02 ; \eta_{\text {partial }}{ }^{2}=.03\right)$ and students in

younger grades $\left(F_{3,186)}=10.07, p<.01 ; \eta_{\text {partial }}{ }^{2}=.14\right)$ were more interested at both preand post. In other words, there was a slight main effect for race and grade-level, but no interaction effects emerged. In sum, students' interest in social studies increased significantly from pre to post; although some subgroups were more interested than others at the outset, all subgroups became more interested by the end of the simulation.

[INSERT FIGURE 1 ABOUT HERE] 
We posed four hypotheses as to why this change in interest might have occurred. First, it appeared that students might become more interested in social studies because they became particularly engaged with their issue area. The descriptive statistics in Table 1 indicate that at the time of the initial assessment, students were more interested in their issue area than the other topics. However, by the end of the simulation, students for all five topic areas were less interested in their topic than they had been at the start of the simulation. In other words, while there was a significant increase in interest in social studies overall, students were actually becoming less interested in their specific issue area. Thus, we found no evidence to support first hypothesis. If anything, there appears to be a trend that students become disenchanted with their own topic area.

\section{[INSERT TABLE 1 ABOUT HERE]}

Second, we hypothesized that students might come to view social studies as more interesting as they realize how important the discipline is during the simulation. Students' perceptions of social studies’ importance relative to other subject areas increases significantly over the course of the simulation $\left(t_{(196)}=2.76, p<.01\right.$; Cohen's $\left.d=.21\right)$, although this increase still left social studies ranked as the least important subject. Because we were only interested in students' responses to social studies and because both pre- and post distributions were approximately normal, students reported values for these items function similarly to any rating scale (for which parametric approaches are frequently used). However, some might argue that a nonparametric approach would be more appropriate. Analyzing the data by comparing the pre and post distribution of responses (using a McNemar-Bowker test of symmetry) yielded a similar significant result $\left(\chi^{2}{ }_{(6, N}=\right.$ $197)=14.30, p=.03)$. In terms of raw numbers this trend meant that over the course of the simulation 71 students came to view social studies as more important, 92 maintained the same opinion, and 35 viewed it as less important relative to other subjects. Thus, students' perceptions of the import of social studies changed over the course of the simulation.

In determining whether this change was related to their increase interest in social studies, preliminary analyses showed that these measures were correlated before $\left(r_{(195)}=\right.$ - 
$.24, p<.01)$ and at the end $\left(r_{(195)}=-.28, p<.01\right)$ of the simulation (because we are correlating ranking and rating items, a negative $r$ indicates a positive association between the variables). To test whether this increase in perceived importance related to students' increased interest in social studies, we regressed students' Interest in social studies (post) on the change in importance scores while controlling for interest in social studies (pre). Change in importance was not a significant predictor in this regression equation (standardized $\beta=.00, t=.07, p=.95$ ). Thus, we did not find support for the second hypothesis.

The third hypothesis posited that, through the simulation, students would come to view social studies as more (optimally) challenging than they had originally thought. This appreciation of the challenges in the simulation may have sparked an increase in students' interest in the subject matter more generally. In exploring this possibility, we first examined the extent to which students' self-efficacy in social studies changed over the course of the simulation. The data showed a decline in students' self-efficacy from pre ( $M$ $=3.73)$ to post $\left(M=3.58 ; t_{(197)}=3.32, p<.01\right.$; Cohen's $\left.d=.22\right)$. Correlations indicated that self-efficacy and interest were related before $\left(r_{(191)}=.47, p<.01\right)$ and at the end $\left(r_{(187)}\right.$ $=.43, p<.01$ ) of the simulation. To investigate whether this decline in self-efficacy predicted their increased interest in social studies, we regressed students' Interest in social studies (post) on the change in their self-efficacy scores while controlling for interest in social studies (pre). Change in self-efficacy was a significant predictor in the regression (standardized $\beta=-.15, t=-2.94, p<.01$ ). Thus, we retained the third hypothesis as plausible.

Finally, we hypothesized that as students increasingly engaged in SPT, their interest in social studies may increase. We found that students' SPT increased slightly over the course of the simulation $\left(M=3.24\right.$ pre, $M=3.32$ post; $t_{(189)}=1.75, p=.08$; Cohen's $d=.11)^{1}$. SPT and interest correlated moderately before $\left(r_{(193)}=.37, p<.01\right)$ and at the end $\left(r_{(197)}=.49, p<.01\right)$ of the simulation. To test the plausibility that the increase in SPT might help explain the increase in interest in social studies, we regressed students’ Interest in social studies (post) on their change in SPT while controlling for Interest in

\footnotetext{
${ }^{1}$ All $p$-values reported are two-tailed tests. Because the simulation encourages students to engage in SPT, the only reasonable hypothesis is that it might increase during the simulation. Thus, a one-tailed test seems appropriate in this instance (which results in p-value of less than .05).
} 
INCREASING INTEREST IN SOCIAL STUDIES

social studies (pre). Change in SPT was a significant predictor in the regression (standardized $\beta=.25, t=5.44, p<.01$ ). Thus, we retained the fourth hypothesis as plausible.

With the testing of these hypotheses completed, we conducted an additional analysis to investigate the simultaneous relationship between those variables that appeared to play a role in students' changing levels of interest. Specifically, we conducted a path analysis that included students' race and grade-level as exogenous variables; gender was excluded because it showed no main effects in the initial analysis. The remaining variables included pre- and post- measures of students' interest, change in self-efficacy in social studies, and change in SPT. As Figure 2 illustrates, students' increases in SPT and decreases in self-efficacy related to their final level of interest while controlling for initial interest. Overall the path model in Figure 2 fit the data well $\left(\chi^{2}{ }_{(8)}=6.097, \mathrm{p}=.636\right.$; CFI $=$ 1.00 ; RMSEA $=.00$ ) and explains $64 \%$ of the variance in students interest in social studies by the end of the simulation.

\section{[INSERT FIGURE 2 ABOUT HERE]}

\section{$\underline{\text { Discussion }}$}

Although previous research has demonstrated that simulations can be effective learning tools for higher education and for science classrooms, less is known about the extent to which simulations might improve motivational outcomes for students. There is reason to think that the few studies indicating motivational benefits of simulations in higher education and science settings may not generalize to the particularly challenging context of middle school social studies. This study demonstrated that the use of a role playing simulation in this particularly challenging environment may help bolster students' interest in the subject matter. However, the study found no evidence that the increase in student interest was due to students' increased interest in their particular area of expertise or to their increased valuing of social studies as an important subject matter. The increase in interest was related to a decline in students' self-efficacy for social studies and to an increase in SPT propensity. Thus a causal connection between these latter two variables and an increase in student interest remains plausible. The final section of this article 
discusses these results, including what their implications for future research and for practitioners, and describes three limitations that particularly warrant mention.

Hypothesized mechanisms. First, we revisit the explanations posited in the introduction as to how different factors might impact student interest in social studies. Although the first hypothesis did not receive support in this study, the idea that students might get interested in a particular area that they studied and that interest may generalize to the larger domain may still be viable. One possibility is that students in the GlobalEd simulation spent so much time on their issue area, that they experienced some level of burnout. Alternatively, as they increasingly interacted with their classmates and began to learn more about the other topics that they were studying, they may have become more curious about areas that they knew less about. In other words, students may not have grown disenchanted with their particular issue area, but rather they grew more intrigued with the other topics. Although ranking items have some advantages over the use of rating items (Krosnick \& Alwin, 1988), one drawback is that they provide relative, rather than absolute information. On the other hand, it is possible that interests do not necessarily transfer between broader domains and sub-domains. Just because students become interested in a specific issue such as Brazil's environmental policies, does not mean that this interest will transfer to the larger domain of social studies. Research has shown transfer of learning to be challenging for educators to achieve (Mayer \& Wittrock, 1996) the same may hold true for transfer of interest.

Our investigation of the second hypothesis found that while students' did view social studies as relatively more important by the end of the simulation, this increased valuing of the discipline was not associated with the increase in interest. We find this result puzzling. Eccles-Parsons et al. (1983) expectancy-value theory posits a close connection between these two constructs - specifically that interest is one way in which students might value an activity. One possibility is that interest in social studies makes students view the subject matter as more important but that the causal path does not flow in the reverse. However, our data do not support that contention (Importance at Time 1 relates to Interest at Time 2 just as much as Interest at Time 1 relates to Importance at 
Time 2; $r s_{(197 \& \text { 192) }}=-.26 \&-.27$ respectively $\left.^{2}\right)$. Alternatively, it may be that the simulation prompted students to view social studies as more important because they saw its utility value in helping them develop skills such as independent research. However, the reason they became more interested in social studies was for a completely separate reason, such as the intrinsic enjoyment of the social process of negotiating. A final possibility is that a methodological issue, such as the measure of change in importance being unreliable (see the Limitations section below), accounts for the lack of relationship.

We did find support for our third hypothesis that as students found social studies to be more challenging during the GlobalEd simulation, they found it more interesting. Ford's (1992) concept of optimal challenge offers one compelling explanation of this result. Historically, students have perceived social studies as not just boring, but not as challenging as other subjects such as math (Stodolsky et al., 1991). Thus, to the extent that the simulation makes students perceive the subject area as harder than they realized and correspondingly modify their perceptions of their social studies ability, they may become more interested in the discipline. One potential flaw in this explanation is that there may be problems in equating declining self-efficacy with students' perceiving social studies as more closely approximating an optimal challenge. Students’ self-efficacy may drop because of changes that they attribute to themselves (e.g., their grades are dropping in all their subjects because they no longer have enough time to study) rather than to their environment. However, if this drop in self-efficacy is due to an internal factor, it is hard to know why it would correlate with the rise in interest. Alternatively, some third factor besides the simulation might cause both the drop in self-efficacy and the increase in interest. For example, an exciting, dynamic teacher who was challenging and a hard grader might be responsible for both results. This particular possibility seems unlikely given that students would be habituated to their teachers by the middle of the year when the pre- and post-assessments were taken.

The final hypothesis posits that students’ increased propensity to engage in SPT might relate to their increased interest. The GlobalEd simulation encourages students to practice this skill as they negotiate with others. SPT is important to their success and

\footnotetext{
${ }^{2}$ Because these correlations are between rating and ranking items, a negative relationship indicates a positive relationship.
} 
learning in the simulation as well as being a developmentally important and appropriate task. Thus, as students begin to see their classroom environment reward that which they may already intrinsically motivated to do, their affect towards social studies may improve and they may become more interested in the subject. Alternatively, solving the puzzle of what other people are thinking and feeling may be particularly motivating at the level of understanding more about the different cultures they are learning about during the simulation. When students realize that SPT propensity plays an important role in understanding people from different cultures, their interest in the discipline increases. In other words, a positive relationship between increased SPT and increased interest in social studies could emerge at the social level of the negotiations or at the level of the content of the simulation's curriculum.

As a final note on the interpretation of these findings, we should underscore that the null findings of the first two hypotheses or the significant findings of the latter two hypotheses do not disprove or prove the underlying theories. The study was not designed to test the relative predictive power of different theories. Thus, these findings should be seen as single instances in which the respective theories did or did not provide plausible explanations of what happened. Different subject areas, different age groups, and different simulations could all lead to different findings.

Implications for research and practice. Non-experimental studies such as this one lend themselves more readily to ideas for future research than they do to ideas for practitioners. Without a randomly assigned treatment and control group, we are not in a position to make causal claims. This fact simultaneously provides an obvious candidate for a future study (i.e., do an experiment), and severely limits what researchers might tell practitioners with authority. With this imbalance in mind, we attempt to describe an approach to future research that we view as promising and try to extract reasonable lessons for practitioners without overstepping the bounds of our data.

The most important finding that future studies of GlobalEd or comparable simulations could provide would be that students' participation in the simulation caused them to be more motivated, more interested, or to achieve more highly. The experimental study that could provide such information is challenging to conduct, however. Few teachers are willing to have their classes randomly assigned to a control group, and even 
fewer teachers will behave equivalently regardless of whether they are teaching a treatment or control classroom. Thus, although a randomized experiment is probably the most important future study for this line of research, it is also probably the most difficult to execute with fidelity.

A slightly different approach would allow for valuable causal data to be collected on findings of particular interest and might qualify as the next best option. By focusing on the student groups as the unit of analysis, future studies might take advantage of random assignment. In other words, within the same teacher's classroom the Human Rights group might be assigned to treatment while the Global Environment group would be assigned to control, and so on. Interventions could be administered by the SIMCON as email messages or through a special log-in code that would direct different groups towards different sets of resource materials. Through these designs, we could then address questions such as, whether different levels of difficulty in the materials affect students' self-efficacy and, by extension, impact their interest in social studies. By designing an intervention that bolster's students’ propensity to engage in SPT, we could also see whether those students become more interested in social studies. In short, a promising future direction for these types of simulations might compare groups within the simulation rather than trying to compare the simulation to traditional classroom instruction. This approach would not allow educators to assess the overall efficacy of the simulation; a matched-pairs design would be a more appropriate approach for a replication study. However, this approach of conducting experiments within the simulation would have the added benefit of providing data that could help improve the simulation's impact on students over time.

These possibilities for future research could result in several important findings for educators. However, in the mean time, social studies teachers continue to conduct classes and need to decide whether to participate in simulations such as GlobalEd based upon correlational findings. Not only do teachers need to make decisions based on imperfect information, but their decision-making calculus also differs from that of researchers. As researchers, we often have the luxury of chipping away at a problem with multiple studies until we are satisfied with the veracity of an answer. However, as teachers, we must continually make probabilistic decisions based upon what we think will work best for our 
students using whatever data are available. Interpreting the results of this study through a practitioner's lens leads us to frame the discussion of the results differently.

As researchers we had a theoretical interest in interest as an outcome variable. For teachers, we think it makes more sense to view the study as having a constellation of outcome variables. Specifically, the data show that during the simulation students: came to view social studies as more important, decreased in their self-efficacy (in a way that may have been beneficial), increased their propensity to engage in SPT, and became more interested in social studies. They also became less interested in their particular issue area relative to the other issue areas (perhaps because they spent so long on their topic). So if teachers were to have their classes participate in a simulation like GlobalEd, they may anticipate multiple outcomes from their participation. We do not know that the simulation caused these outcomes. However, we can probably rule out certain competing explanations for these outcomes. For example, it seems unlikely that these changes were caused by teachers. Students had several months to habituate to their teachers before beginning the simulation and the degree to which teachers sparked students' interest in social studies should be reflected in their initial interest scores. Other potential explanations cannot be ruled out. For example, these results might be caused not by the activity of the simulation but by the curricular materials provided by GlobalEd. Alternatively, these results might stem from the mere act of doing something novel to change the pace of the class at that point in the year. Although most researchers might be disappointed in these last two explanations, they may not dissuade teachers from participating (i.e., their classes would still reap the same benefits by participating). Assuming these outcomes consistently co-occur with participation in a simulation such as GlobalEd, it is important to remember that more outcomes than just student interest are stake.

In addition to taking a more inclusive view of what the "outcomes" of the study are, we encourage teachers to assess the risks that might be involved in having their classes participate. For example, although we do not know that participating in GlobalEd will cause students to become more interested in social studies, our data indicate that it is highly unlikely that students will become less interested in social studies as a result of participating in this simulation. Similarly, it seems very unlikely that students will 
experience declines in their valuing of social studies or their propensity to engage in SPT. Instead the risks seem to be that students' might experience a drop in their social studies self-efficacy, and that they might come to view their topic as less interesting. We have hypothesized that the first "risk" might normatively be viewed as a positive i.e., the drop in self-efficacy might represent a shift towards students’ perceiving an optimal level of challenge. The second risk may be a consequence of burnout or of increased interest in other topics. The data from the study simply do not allow us to further evaluate these risks. In addition to evaluating these results, teachers may wish to weigh whether the learning gains demonstrated by this sample of students seem worth whatever additional efforts might be required by participating in the simulation. Because several of the effect sizes are relatively small (e.g., the magnitude of the increase in interest), teachers' expectations regarding the impact of the intervention should be accordingly modest. Furthermore, teachers volunteered their classes to participate in the simulation and thus the types of teachers who led these classes are unlikely to represent the broader population of middle school social studies teachers. In sum, we encourage teachers to evaluate the results of this study through a different lens than researchers and to think through these results with the idiosyncrasies of their particular students in mind.

Limitations. Finally, we would like to address three limitations of the study that may be weighing on readers' minds. First, as alluded to earlier, the use of change scores can be problematic. Although some scholars recommend against the use of change scores, under certain circumstances their use may be appropriate (Gardner \& Neufeld, 1987; Rogosa \& Willett, 1983). A primary concern regards the likelihood that change scores will be unreliable. In the case of the third and fourth hypotheses, we did compute reliabilities for change in self-efficacy $(\alpha=.55)$ and SPT $(\alpha=.65)$. Though these are lower than generally recommended, it seems relatively unlikely that these alpha levels are at such a low level so as to invalidate our findings. In fact, it is more likely that the lack of reliability in these scores has diminished the strength of their relationship with interest. In testing the first two hypotheses, we could not assess the reliability of the change in importance because we had no means to assess the reliability of a single ranking item. Thus, the first two findings should be interpreted with corresponding caution. 
A second concern for some readers may be the lack of a comparison group. The finding that provides the foundation for the study is the increase in student interest that is associated with participation in the GlobalEd simulation. We do not know for sure what would have happened to an equivalent group of students who was not participating in the simulation over that same period of time. However, given the pervasiveness and consistency with which adolescents' motivation and interest in school declines, especially during middle school (Wigfield et al., 2006), we feel that it is very unlikely that students' interest would have increased spontaneously at that point in the year.

Finally, it is reasonable to accept as plausible that the simulation may have played a role in causing the increase in students' interest, but still have concerns regarding students' learning. In other words, educators might be excited about the prospect of a simulation that is associated with increases in student interest but be unwilling to try it out if students are not learning anything. The present study assessed content knowledge through a multiple choice test and found that students improved their scores significantly on the assessment $\left(t_{(188)}=5.92, p<.01\right.$; Cohen's $\left.d=.43\right)$. Although the magnitude of these learning gains is modest, the students' content knowledge clearly increased over the course of the simulation. Unfortunately, we did not include other learning assessments that might have been more closely aligned with the types of learning that occurred during the simulations (e.g., procedural knowledge related to negotiation). A more comprehensive assessment of the learning that occurs in this type of simulation (and its relation to student interest) is an additional issue that warrants further exploration in future studies.

Conclusion. Even the most cursory attention to most news outlets will illustrate the importance of social studies in today's world. Whether the reports focus on policymakers debating laws, the role of different religions in national and international conflicts, or the globalized nature of business, it is hard to argue that studying the backgrounds and cultures of different groups of people is trivial. Despite its importance, students have tended to view social studies as particularly uninteresting. If students continue to find this discipline boring, they will likely pursue other disciplines that they find more rewarding as they progress through high school and into college. This type of attrition from social sciences could potentially leave a dearth of skilled personnel at a historical moment when 
globalization is accelerating and understanding individuals from other cultures is paramount.

Thus, it seems critical to help develop students' interest in social studies particularly during their middle school years as this developmental moment may be critical for keeping students motivated. The GlobalEd simulation evaluated here may have reversed the pervasive finding of progressively declining student interest (Pintrich \& Schunk, 2002; Wigfield et al., 2006). We hope that continued investigation and experimentation by researchers and practitioners alike can add more clarity to the potential of simulations like GlobalEd to address this important issue of motivation in social studies. 
INCREASING INTEREST IN SOCIAL STUDIES

\section{References:}

Alexander, P. A., Schulze, S. K., \& Kulikowich, J. M. (1994). How subject-matter knowledge affects recall and interest. American Educational Research Journal, 31(2), 313-337.

Alleman, J., \& Brophy, J. (1993). Teaching that lasts: College students' reports of learning activities experienced in elementary school social studies. Social Science Record, 30(2), 36.

Alleman, J., \& Brophy, J. (1994). Teaching that lasts: College students' reports of learning activities experienced in elementary school social studies. Social Science Record, 31(1), 42.

Csikszentmihalyi, M. (1991). Flow: the psychology of optimal experience (1st HarperPerennial ed.). New York: HarperPerennial.

Davis, M. H. (1996). Empathy: A social psychological approach. Boulder: Westview Press.

Dede, C., Clarke, J., Ketelhut, D. J., Nelson, B., \& Bowman, C. (2005). Fostering motivation, learning, and transfer in multi-user virtual environments. Retrieved January 20, 2007, from http://muve.gse.harvard.edu/rivercityproject/documents/Dede_Games_Symposium _AERA_2005.pdf

Eccles-Parsons, J. S., Adler, T. F., Futterman, R., Goff, S. B., Kaczala, C. M., Meece, J. L., et al. (1983). Expectancies, values, and academic behaviors. In J. T. Spence (Ed.), Achievement and achievement motives: Psychological and sociological approaches (pp. 75-146). San Francisco: W.H. Freeman.

Eccles, J. S., Midgley, C., Wigfield, A., Buchanan, C. M., Reuman, D., Flanagan, C., et al. (1993). Development during adolescence: The impact of stage-environment fit on young adolescents' experiences in schools and in families. Special Issue: Adolescence. American Psychologist, 48(2), 90-101.

Epstein, J. L., \& McPartland, J. M. (1976). The concept and measurement of the quality of school life: American Educational Research Journal.

Ford, M. E. (1992). Motivating humans: Goals, emotions, and personal agency beliefs. Newbury Park, CA: Sage Publications. 
Gardner, R. C., \& Neufeld, R. W. J. (1987). Use of the simple change score in correlational analyses. Educational and Psychological Measurement, 47(4), 849-864.

Hidi, S., \& Renninger, K. A. (2006). The four-phase model of interest development. Educational Psychologist, 41(2), 111-127.

Hope, W. C. (1996). It's time to transform social studies teaching. Social Education, 87(4), $149-151$.

Keating, D. P. (1990). Adolescent thinking. In S. S. Feldman \& G. R. Elliott (Eds.), At the threshold: The developing adolescent. (pp. 54-89). Cambridge: Harvard University Press.

Kobrin, D., Abbott, E., Ellinwood, J., \& Horton, D. (1993). Learning history by doing history. Educational Leadership, 50(7), 39-41.

Krosnick, J. A., \& Alwin, D. F. (1988). A test of the form-resistant correlation hypothesis: Ratings, rankings, and the measurement of values. Public Opinion Quarterly, 52(4), 526-538.

Lay, J. C., \& Smarick, K. J. (2006). Simulating a senate office: The impact on student knowledge and attitudes. Journal of Political Science Education, 2(2), 131-146.

Mayer, R. E., \& Wittrock, M. C. (1996). Problem-solving transfer. In D. C. Berliner \& R. C. Calfee (Eds.), Handbook of educational psychology. (pp. 47-62). New York London: Macmillan Library Reference Usa Prentice Hall International.

Midgley, C., Maehr, M. L., Hruda, L. Z., Anderman, E., Anderman, L., Freeman, K. E., et al. (2000). Patterns of Adaptive Learning Study. Retrieved November 8, 2000, from http://www.umich.edu/ pals/PALS\%202000_V13Word97.pdf

Pace, D., Bishel, B., Beck, R., Holquist, P., \& Makowski, G. (1990). Structure and sponteneity: Pedagogical tensions in the construction of a simulation of the Cuban missle crisis. The History Teacher, 24(1), 53-65.

Pintrich, P. R. (2000). Multiple goals, multiple pathways: The role of goal orientation in learning and achievement. Journal of Educational Psychology, 92(3), 544-555.

Pintrich, P. R., \& Schunk, D. H. (2002). Motivation in education: Theory, research, and applications (2nd ed.). Upper Saddle River, NJ: Merrill Prentice Hall.

Prensky, M. (2001). Digital game-based learning.: New York: McGraw Hill. 
Putnam, R. (1988). Diplomacy and domestic politics: The logic of two-level games. International Organization, 42(1), 427-460.

Rogosa, D., \& Willett, J. B. (1983). Demonstrating the reliability of the difference score in the measurement of change. Journal of Educational Measurement, 20(4), 335-343.

Ronen, M., \& Eliahu, M. (2000). Simulation - A bridge between theory and reality: The case of electric circuits. Journal of Computer Assisted Learning, 16, 14-26

Schiefele, U. (1996). Topic interest, text representation, and quality of experience. Contemporary Educational Psychology, 21(1), 3-18.

Stodolsky, S. S., Salk, S., \& Glaessner, B. (1991). Student views about learning math and social studies. American Educational Research Journal, 28(1), 89-116.

Symons, C. S., \& Johnson, B. T. (1997). The self-reference effect in memory: A metaanalysis. Psychological Bulletin, 121(3), 371-394.

Tamura, E. H. (1992). Should the minimum drinking age be changed? A simulation on the legislative process. Social Studies., 83(5), 201.

Teague, M., \& Teague, G. (1995). Planning with computers: A social studies simulation. . Learning and Leading With Technology, 23(1), 20-22.

Tracey, T. J. G. (2002). Development of interests and competency beliefs: A 1-year longitudinal study of fifth- to eighth-grade students using the ICA-R and structural equation modeling. Journal of Counseling Psychology, 49(2), 148-163.

VanSledright, B., \& Limon, M. (2006). Learning and teaching social studies: A review of cognitive research in history and geography. In P. A. Alexander \& P. H. Winne (Eds.), Handbook of educational psychology (2nd ed., pp. 545-570). Mahwah, N.J.: Lawrence Erlbaum.

Watt, H. M. G. (2004). Development of adolescents' self-perceptions, values, and task perceptions according to gender and domain in 7th- through llth-grade Australian students. Child Development, 75(5), 1556-1574.

White, R. W. (1959). Motivation reconsidered: The concept of competence. Psychological Review, 66, 297-333.

Wigfield, A., Byrnes, J. P., \& Eccles, J. S. (2006). Development during early and middle adolescence. In P. A. Alexander \& P. H. Winne (Eds.), Handbook of educational psychology (2nd ed., pp. 87-113). Mahwah, NJ: Lawrence Erlbaum. 
Wolters, C. A., \& Pintrich, P. R. (1998). Contextual differences in student motivation and self-regulated learning in mathematics, English, and social studies classrooms. Instructional Science, 26(1-2), 27-47. 


\section{Appendix}

1) Social studies interest -6 items

Pre $\alpha=.85, \mathrm{~m}=3.35, \mathrm{sd}=.78$

Post $\alpha=.87, \mathrm{~m}=3.49, \mathrm{sd}=.78$

Response scale:

$\begin{array}{ccccc}\text { not at all } & \text { slightly } & \text { moderately } & \text { quite } & \text { extremely } \\ \text { interesting } & \text { interesting } & \text { interesting } & \text { interesting } & \text { interesting }\end{array}$

Items:

Overall, how interesting do you find your social studies class?

When you hear about current events in the news, how interesting do you find them?

How interesting do you find learning about other countries?

How interesting are the different topics you study in this class?

How interesting are the assignments you are given for this class?

How interesting do you find learning about international conflicts?

\section{2) Interest in issue area:}

Please rank your interest in the following topics so that $1=$ the most interesting to you and

5 = least interesting to you:

Immigration
International Economics
Global Environment
Human Rights
Conflict and Cooperation

\section{3) Importance of social studies:}

Please rank the following subjects where $1=$ most important to $4=$ least important to you.

English
Math
Science
Social Studies




\section{4) Social Studies Self Efficacy: 5 items}

Pre $\alpha=.79, \mathrm{~m}=3.73, \mathrm{sd}=.65$

Post $\alpha=.82, \mathrm{~m}=3.58, \mathrm{sd}=.72$

Response Scale:

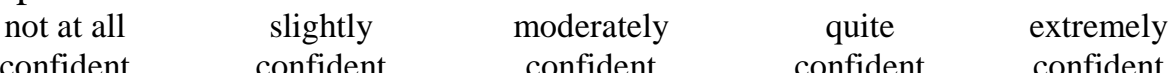

How confident are you that you can learn all the material presented in this class?

How confident are you that you can do the hardest work that is assigned in this class?

When complicated ideas are presented in this class, how confident are you that you can understand them?

How confident are you that you can complete all the work that is assigned in this class?

How confident are you that you will remember what you learned in this class next year?

5) SPT-Propensity- 7 items

Pre $\alpha=.88, \mathrm{~m}=3.25, \mathrm{sd}=.75$

Post $\alpha=.88, \mathrm{~m}=3.31, \mathrm{sd}=.76$

Response Scale:

\begin{tabular}{|c|c|}
\hline $\begin{array}{c}\text { almost } \\
\text { never }\end{array}$ & $\begin{array}{l}\text { once in } \\
\text { a while }\end{array}$ \\
\hline
\end{tabular}

How often do you try to figure out how the people around you view different situations? If you are having a disagreement with your friends, how often do you try to imagine how they are feeling?

How often do you try to look at everybody's side of a disagreement before you make a decision?

When you are upset at someone, how often do you try to "put yourself in his or her shoes"? How often do you try to understand your classmates better by trying to figure out what they are thinking?

Before criticizing others, how often do you imagine how you would feel if you were in their place?

To understand your friends better, how often do you imagine how things look from their perspective? 
INCREASING INTEREST IN SOCIAL STUDIES

Table 1: Descriptive statistics for students' rankings of their relative interest in topic areas

\begin{tabular}{llllc}
\hline & $\mathrm{N}$ & Pre Mean & Post Mean & Difference \\
\hline Conflict \& Cooperation & 38 & 2.11 & 2.55 & -.45 \\
Others & 161 & 3.18 & 3.12 & .06 \\
Global Environment & 43 & 1.88 & 2.56 & -.67 \\
Others & 155 & 2.82 & 2.76 & .06 \\
& & & & \\
Human Rights & 45 & 1.42 & 1.84 & -.42 \\
Others & 154 & 2.56 & 2.49 & .07 \\
& & & & -.58 \\
International Economics & 34 & 2.38 & 2.97 & .33 \\
Others & 164 & 3.62 & 3.29 & .41 \\
\hline U.N. Security Council Reform & 37 & 2.22 & 2.84 & \\
Others & 161 & 3.93 & 3.52 & \\
\hline
\end{tabular}

Note: Because these are ranking items, lower numbers correspond to higher rankings. A negative difference score indicates that students became less interested in their topic relative to the other topics.

Between-group comparisons (e.g., those students in the Conflict \& Cooperation issue area vs. all other students) can be made by looking down columns. Within-group comparisons can be made by looking across rows (e.g., those students in the Global Environment topic area became less interested in their topic from pre to post). 
Figure 1: Average gains in interest by teacher

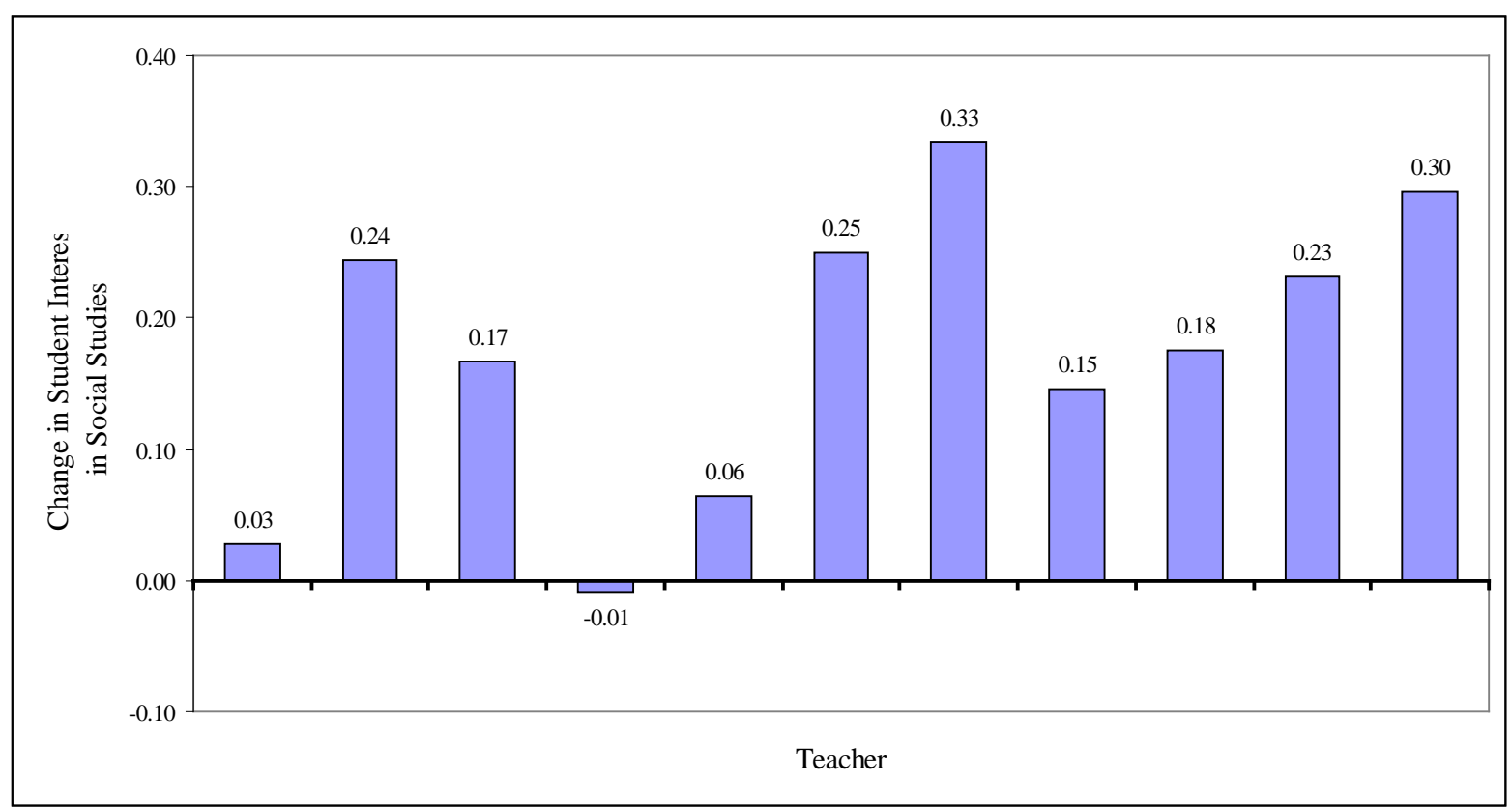


Figure 2: Path diagram predicting interest at the end of the simulation

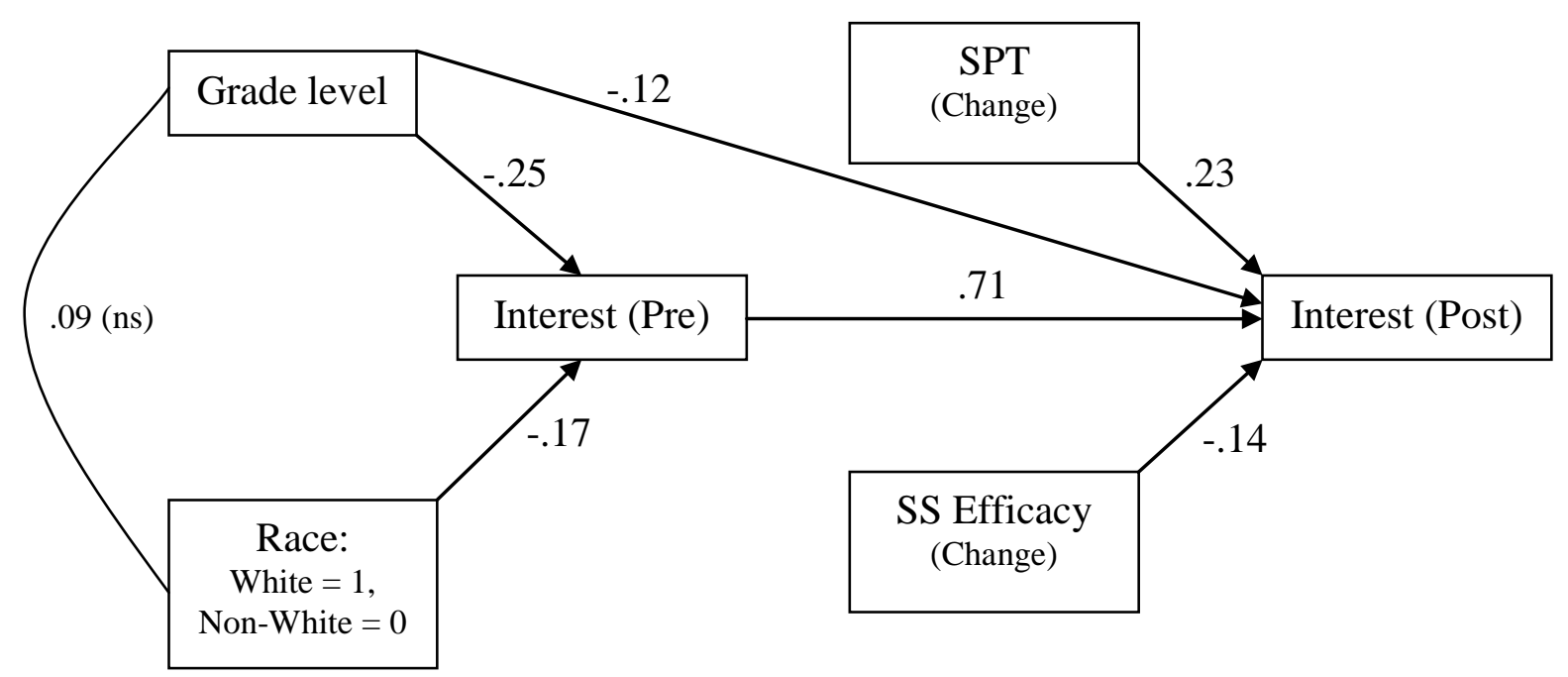

